TI 2002-090/3

Tinbergen Institute Discussion Paper

Worker Reciprocity and

Employer Investment in Training

Edwin Leuven ${ }^{1,2}$

Hessel Oosterbeek ${ }^{1,2}$

Randolph Sloofl,2

Chris van Klaveren'

${ }^{\prime}$ Faculty of Economics and Econometrics, University of Amsterdam,

2 Tinbergen Institute 
Tinbergen Institute

The Tinbergen Institute is the institute for economic research of the Erasmus Universiteit Rotterdam, Universiteit van Amsterdam and

Vrije Universiteit Amsterdam.

Tinbergen I nstitute Amsterdam

Keizersgracht 482

1017 EG Amsterdam

The Netherlands

Tel.: +31.(0)20.5513500

Fax: $\quad+31 .(0) 20.5513555$

Tinbergen Institute Rotterdam

Burg. Oudlaan 50

3062 PA Rotterdam

The Netherlands

Tel.: $\quad+31 .(0) 10.4088900$

Fax: $\quad+31 .(0) 10.4089031$

Most TI discussion papers can be downloaded at

http://www.tinbergen.nl 


\title{
Worker reciprocity and employer investment in training*
}

\author{
Edwin Leuven Hessel Oosterbeek Randolph Sloof \\ Chris van Klaveren
}

\begin{abstract}
Standard economic theory predicts that firms will not invest in general training and will underinvest in specific training. Empirical evidence indicates, however, that firms do invest in general training of their workers and also points to no underinvestment in specific training. We propose a simple model in which a firm invests the socially optimal amounts in general and specific training if the worker is sufficiently motivated by reciprocity. A reciprocal worker may be willing to give the firm the full return on its investment. We present empirical evidence that is strongly supportive for the proposed mechanism. Workers with a high sensitivity to reciprocity have 15 percent higher training rates than workers with a low sensitivity to reciprocity.
\end{abstract}

JEL Codes: J41

Keywords: Training; Reciprocity

\section{Introduction}

Standard economic theory predicts that without appropriate measures being taken, firms will not invest in general training and will underinvest in firm-specific training. The zero investment of firms in general training results from the fact that workers will be able to reap the entire benefits of such training (cf. Becker, 1962). Underinvestment

${ }^{*}$ University of Amsterdam, Roetersstraat 11, 1018 WB Amsterdam, The Netherlands and NWO Priority Program 'Scholar'. Oosterbeek and Sloof are also affiliated with the Tinbergen Institute. This version: June 2002. 
in specific training results when firms and workers are unable to write binding contracts that condition post-training wages on the level of investment. This is an application of the holdup problem (cf. Williamson, 1985).

Empirical evidence casts doubt on firms' underinvestment in training. There are indications that firms actually do invest in general training and that the high (wage) returns to training are probably not as large as has been suggested. Acemoglu and Pischke (1998) and Pischke (2001) show that in Germany firms voluntarily offer apprenticeships to their workers. The skills provided in these programs are highly general, but firms bear a considerable fraction of the costs of training. Leuven and Oosterbeek (1999) show that in Canada, The Netherlands, Switzerland and the United States, firms often pay for the direct costs of training when the worker initiated the training and/or if this training is provided outside the firm. Booth and Bryan (2002) report that in the United Kingdom, employers often pay for training which the recipients view as general.

Furthermore, recent studies of the wage returns to training question the occurrence of underinvestment in training. High returns to training can be interpreted as an indication of underinvestment is training. In this respect some have referred to high wage returns to training. These wage returns may however be biased due to endogeneity of training participation. Leuven and Oosterbeek (2002a,b) present selectivity corrected estimates of the wage return to training. Leuven and Oosterbeek (2002a) use an IV approach where the instrument is derived from a discontinuity in the tax deduction for firms of the costs of training. This tax deduction is substantially higher for workers older than 40 years than for workers younger than 40 years. Leuven and Oosterbeek (2002b) present estimates of the wage returns to training when the control group of untrained workers is reduced to workers who wanted to participate in training but did not do so due to some random event. In both studies the wage returns to training are much smaller than in cases where there is no correction for selectivity bias (cf. Frazis and Loewenstein, 1999).

To provide a theoretical underpinning of firms' willingness to invest in general training Katz and Ziderman (1990); Stevens (1994, 1996); Acemoglu and Pischke (1999); Booth and Zoega (1998) all present models in which firms may pay for general training. The common feature of these models is some market imperfection that causes a situation in which wages are compressed relative to productivity.

The lack of underinvestment in training can also be explained by the fact that par- 
ties have made arrangements to alleviate such underinvestment. Such arrangements include the introduction of up-or-out contracts (cf. Kahn and Huberman, 1988; Oosterbeek et al., 2001), restructuring of the ex post bargaining process such that the investing party becomes residual claimant (cf. Aghion et al., 1994), or the introduction into the contract of breach remedies (cf. Shavell, 1980; Chung, 1992; Sloof et al., 2002)

In this paper we focus on an alternative explanation for the lack of underinvestment in training by firms. In the standard model, the firm does not invest in general training and underinvests in specific training because it anticipates opportunistic behavior of its workers. A large body of empirical evidence obtained in laboratory experiments shows, however, that a substantial fraction of subjects behave as if they are motivated by other factors besides their own monetary payoffs. Inequity aversion, fairness and reciprocity are such alternative motivations (cf. Fehr and Gächter, 2000).

In this paper we test a model based on reciprocity. Reciprocity entails that a person is willing to sacrifice some monetary payoff in order to reward someone who has been kind toward him or to punish someone who has been unkind. When a firm invests more in a worker's skills than theory predicts, the worker may interpret this as a kind action of the firm which deserves some reward. The worker can give this reward by behaving less opportunistically than standard theory assumes him to do. If the firm anticipates this kindness it will be prepared to invest more (underinvest less).

In the next section we develop this argument more formally. The analysis is based on the theory of sequential reciprocity introduced by Dufwenberg and Kirchsteiger (2001). We formally show that a firm may invest the socially efficient amounts of general training and specific training if the worker is sufficiently motivated by reciprocity. The main novelty of this paper, however, is the introduction of a measure of reciprocity in the empirical training literature. In a recently held survey concerning training we included a question about the reciprocal attitudes of the respondents. Results show that workers who are more inclined to act reciprocal are substantially more likely to participate in a training course during the 12 months prior to the interview. This remains to be the case if we control for a large number of covariates or if we adapt the measurement of training. Our empirical evidence thus strongly supports the relevance of the proposed reciprocity mechanism.

The remainder of this paper is organized as follows. The next section presents a simple standard economic model of firms' investment in training. In this model firms are not prepared to invest in general training and underinvest in specific train- 
ing. The section then continues by analyzing this model in the context of Dufwenberg and Kirchsteiger's theory of sequential reciprocity. Section 3 contains the main (and empirical) part of the paper. It first describes the data and especially how we measure training and reciprocity. It then presents and discusses the empirical results. Section 4 summarizes and concludes.

\section{Theory}

\subsection{Firms' investment in training when parties are selfish}

Consider the following simple two-stage model. There are two parties: a firm and a worker. In the first stage the firm chooses how much to invest in general $\left(I_{g}\right)$ and specific training $\left(I_{S}\right)$ of the worker, where investment levels are measured in money terms.

We assume that the worker does not invest, for instance because he is liquidity constrained. The firm's investment choice determines the worker's productivity within and outside the firm. Worker's productivity within the current firm equals $V_{F}=V_{0}+$ $G\left(I_{g}\right)+S\left(I_{s}\right)$; worker's productivity outside the firm equals $V_{A}=V_{0}+G\left(I_{g}\right)$. Here the functions $G(\cdot)$ and $S(\cdot)$ are assumed to be increasing and strictly concave, with $G(0)=$ $S(0)=0$ and $G^{\prime}(0)>1$ and $S^{\prime}(0)>1$ (primes are used to denote derivatives).

In the second stage the firm and the worker negotiate about the worker's wage. The bargaining stage is assumed to result in the generalized Nash bargaining solution. This means that both parties receive their threat point payoffs and that the remaining surplus is divided in proportion to the parties' bargaining power. The gross surplus equals $V_{F}$, the firm's threat point is normalized to zero and the worker's threat point equals $V_{A}$. The net payoffs of the firm are then equal to $\pi_{F}=\alpha_{F} S\left(I_{S}\right)-I_{g}-I_{S}$, while the net payoffs of the worker are equal to $\pi_{W}=V_{0}+G\left(I_{g}\right)+\left(1-\alpha_{F}\right) S\left(I_{S}\right)$. Here $\alpha_{F}$ is a measure of the firm's relative bargaining power (with $0 \leq \alpha_{F} \leq 1$ ).

The firm maximizes its net payoffs and thus chooses $I_{g}^{\text {Nash }}=0$ and $I_{s}^{\text {Nash }}$, where the latter is the unique solution to:

$$
S^{\prime}\left(I_{S}\right)=\frac{1}{\alpha_{F}} .
$$

If $S^{\prime}(0)<1 / \alpha_{F}$, then $I_{S}^{N a s h}=0$. The superscript Nash indicates that these investment levels belong to the situation in which bargaining always results in the Nash bargaining solution. 
If the worker has some bargaining power $\left(\alpha_{F}<1\right)$, both investment levels fall short of the efficient levels $I_{g}^{e f f}$ and $I_{S}^{e f f}$. These are given by the solutions to respectively:

$$
G^{\prime}\left(I_{g}\right)=1 \text { and } S^{\prime}\left(I_{S}\right)=1 \text {. }
$$

While the model presented above is very stylized, it contains the essential features that cause zero investment by the employer in general training and underinvestment in specific training in more complicated settings. The key determinant of no investment in general training by the employer is that the worker can capture the full returns of such training by moving to an alternative employer. The key determinant of underinvestment in specific training is that the parties are unable to write a binding contract that conditions the worker's future wage on the employer's investment in specific training.

\subsection{Firms' investment in training when workers are reciprocal}

This subsection presents a model in which the worker is motivated by reciprocity. We assume that the firm is motivated by profit maximization only, that is, we assume that the firm is not sensitive to reciprocity. The model is an application of the theory of sequential reciprocity as developed by Dufwenberg and Kirchsteiger (2000, 2001). The worker's utility $\left(u_{W}\right)$ is not only determined by the monetary payoffs $\left(\pi_{W}\right)$ but possibly also by a term that expresses reciprocity payoffs $\left(Y_{W} \kappa_{W F} \lambda_{W F W}\right)$. An additive form is assumed:

$$
u_{W}=\pi_{W}+Y_{W} \kappa_{W F} \lambda_{W F W}
$$

The reciprocity term consists of three components. $Y_{W}$ is a non-negative parameter reflecting the worker's sensitivity to reciprocity. $\kappa_{W F}$ represents the worker's kindness toward the firm. It is positive when the worker is kind toward the firm and negative when the worker is unkind toward the firm. $\lambda_{W F W}$ represents the worker's belief about how kind the firm is toward the worker. With this specification it is in the worker's interest to have $\kappa_{W F}$ and $\lambda_{W F W}$ of equal sign. This sign matching is a key ingredient of the model.

We now show that there exists a sequential reciprocity equilibrium in which the firm's investment in training exceeds the amount derived for the situation where the worker is selfish. In particular, we construct an equilibrium in which the firm invests efficiently (this equilibrium need not be unique).

For ease of exposition, assume that the worker chooses between two bargaining 
results only. He can secure himself the Nash bargaining solution and obtain monetary payoffs of $\pi_{W}^{N a s h} \equiv V_{0}+G\left(I_{g}\right)+\left(1-\alpha_{F}\right) S\left(I_{s}\right)$. Alternatively, he chooses to give the firm the full return on her investment and thus earn $\pi_{W}^{\text {Reward }}=V_{0}$ himself. The superscript Reward indicates that with this choice the worker is rewarding the employer for investing efficiently. Assume further that the firm chooses between two pairs of investment levels only, where a pair consists of the level of investment in general and specific training respectively. The firm can either invest the efficient levels $I^{*} \equiv\left(I_{g}^{*}, I_{s}^{*}\right)$, or the levels that are optimal for the firm given selfish behavior of the worker, $I^{\text {Nash }} \equiv\left(0, I_{s}^{\text {Nash }}\right)$.

We next construct the equilibrium. Suppose the firm believes that the worker will choose $\pi_{W}^{\text {Reward }}$ with probability $p$ and $\pi_{W}^{N a s h}$ with probability $(1-p)$ when the firm chooses $I^{*}$. In case it opts for $I^{\text {Nash }}$ the firm believes that the worker chooses $\pi_{W}^{N a s h}$ for sure. Given these beliefs, the firm prefers to invest $I^{*}$ whenever:

$$
p \geq \frac{I_{g}^{*}+\left[\left(\alpha_{F} \cdot S\left(I_{s}^{N a s h}\right)-I_{s}^{N a s h}\right)-\left(\alpha_{F} \cdot S\left(I_{s}^{*}\right)-I_{s}^{*}\right)\right]}{G\left(I_{g}^{*}\right)+\left(1-\alpha_{F}\right) \cdot S\left(I_{s}^{*}\right)}
$$

Because the term within square brackets is necessarily non-negative, necessarily $p>0$ is needed for the firm to prefer $I^{*}$ over $I^{\text {Nash }}$.

Next consider the worker. By choosing $\pi_{W}^{\text {Reward }}$ after $I^{*}$ he gives a payoff of $G\left(I_{g}^{*}\right)+S\left(I_{s}^{*}\right)-\left(I_{g}^{*}+I_{s}^{*}\right)$ to the firm. A choice for $\pi_{W}^{N a s h}$ after $I^{*}$ would yield the firm $\alpha_{F} S\left(I_{s}^{*}\right)-\left(I_{g}^{*}+I_{s}^{*}\right)$. The worker's kindness $\kappa_{W F}$ of a particular choice after $I^{*}$ is now defined as the difference between what he actually gives to the firm, and the average of the maximum and the minimum payoff that he could give to the firm in principle. It follows that:

$$
\kappa_{W F \mid \pi_{W}^{R e w a r d}}=-\kappa_{W F \mid \pi_{W}^{\text {Nash }}}=\frac{1}{2}\left(G\left(I_{g}^{*}\right)+\left(1-\alpha_{F}\right) S\left(I_{s}^{*}\right)\right)
$$

Choosing $\pi_{W}^{\text {Reward }}$ after $I^{*}$ is a kind act of the worker, a choice for $\pi_{W}^{\text {Nash }}$ is interpreted as unkind.

In equilibrium the worker understands the firm's motivation. Hence, the worker's belief about how kind the firm's choice of $I^{*}$ is to him in equilibrium equals the actual kindness of this choice. A reasoning similar to the one above then yields that: 


$$
\begin{aligned}
& \lambda_{W F W \mid I^{*}}=\kappa_{F W \mid I^{*}}= \\
& \quad \frac{1}{2}\left[(1-p)\left(G\left(I_{g}^{*}\right)+\left(1-\alpha_{F}\right) S\left(I_{s}^{*}\right)\right)-\left(1-\alpha_{F}\right) S\left(I_{s}^{\text {Nash }}\right)\right]
\end{aligned}
$$

The firm's kindness $\kappa_{F W}$ is calculated as the difference between what the firm believes she gives to the worker, and the average of the maximum and the minimum payoff that the firm believes she could give to the worker in principle.

With expressions (3) and (4) the worker's utility function $u_{W}$ after $I^{*}$ is completely determined.

Now suppose $p=1$. From (4) then follows that $\lambda_{W F W \mid I^{*}}<0$. In that case the worker prefers $\pi_{W}^{N a s h}$ for sure, contradicting $p=1$. Therefore, necessarily $0<p<1$; the worker must be indifferent between choosing $\pi_{W}^{\text {Reward }}$ and $\pi_{W}^{N a s h}$. By substituting the various terms in the worker's utility function (1) it can be derived that this requires $Y_{W} \cdot \lambda_{W F W \mid I^{*}}=1$, i.e.: ${ }^{1}$

$$
p=\frac{G\left(I_{g}^{*}\right)+\left(1-\alpha_{F}\right) \cdot\left[S\left(I_{s}^{*}\right)-S\left(I_{s}^{N a s h}\right)\right]-2 / Y_{W}}{G\left(I_{g}^{*}\right)+\left(1-\alpha_{F}\right) S\left(I_{s}^{*}\right)}
$$

The requirement on $p$ specified in inequality (2) places a lower bound on the worker's sensitivity to reciprocity:

$$
Y_{W} \geq \frac{2}{\left[G\left(I_{g}^{*}\right)+S\left(I_{s}^{*}\right)-\left(I_{g}^{*}+I_{s}^{*}\right)\right]-\left[S\left(I_{s}^{\text {Nash }}\right)-I_{s}^{\text {Nash }}\right]}
$$

This shows that a sequential reciprocity equilibrium exists in which the firm invests the socially efficient amounts $I_{g}^{*}$ and $I_{s}^{*}$ if the worker's sensitivity to reciprocity is sufficiently high.

\footnotetext{
${ }^{1}$ Formally we also have to check that the worker strictly prefers $\pi_{W}^{N a s h}$ after $I^{N a s h}$. From $\lambda_{W F W \mid I^{N a s h}}=-\lambda_{W F W \mid I^{*}}$ it follows that for this value of $p$ the firm's choice for $I^{\text {Nash }}$ is interpreted as unkind. In that case, the worker wants to punish the firm and will do so by always choosing $\pi_{W}^{N a s h}$ after $I^{\text {Nash }}$. Hence the supposed beliefs of the firm are correct.
} 


\section{Empirical evidence}

\subsection{Data}

The analysis of the previous section implies that a worker's sensitivity to reciprocity may affect a firm's willingness to invest in training of this worker. In this section we test this implication by relating workers' participation in training to their sensitivity to reciprocity. For this purpose we use data that were collected in January and February of 2001. Interviews were held by telephone using computer-aided techniques. The data are a representative sample of the Dutch population aged 16-64. The employed persons were asked questions concerning various background characteristics such as age, gender and formal education. They also responded to an extensive set of questions about the training activities they undertook in the 12 months prior to the interview. Finally, the questionnaire also included a question measuring respondents' sensitivity to reciprocity (their $Y_{W}$ 's).

Training participation is measured by the response to the following question: "Did you spend time following a course/training for purposes of your work or career opportunities during the past 12 months?" Of the 3127 respondents in the sample who held a job, 1393 (45 percent) gave an affirmative answer to this question.

The prediction we want to test in this section relates to firms' willingness to invest in training of their workers. This requires information about the party that paid the costs of the worker's training participation. For up to three training events that a worker followed during the past 12 months, it was asked which party paid the direct costs of training. This gives information about a total of 2200 training events. In 78 percent of the training events, respondents say that the employer paid the full direct costs of training. For another 3 percent of the events, it is said that the employer and the worker shared the direct training costs. (For 14 percent of the events the worker paid the full direct costs and in 5 percent of the cases these costs were borne by another party.)

A second measure of firms' investment in training is the opportunity costs in the form of forgone productivity. Of the 2200 training events, 41 percent occur completely during work time. Another 25 percent of the training events occur partially during work time, with on average 56 percent of the training time during work time. 33 percent of the training events take place completely outside work time. When this happens employers compensate the workers for their forgone leisure in 15 percent of the spells. Taking the information about the direct costs and the time costs together, it 
occurs in only 12 percent of the training events that the employer does not contribute to the training costs at all. It should be noted, however, that the information from these questions does not really prove that the employer actually bear the costs of training. It is possible that workers bear the full costs in the form of a reduction of their wages. We have no information to discard this possibility.

We use the information on firms' contribution to the direct costs and the opportunity costs to construct a dichotomous variable indicating whether the worker participated in firm-sponsored training (1213 respondents) or didn't participate in training at all (1734 respondents). This variable is thus not defined for workers who participated in training to which the firm did not contribute at all (180 respondents).

The main novelty of the analysis in this paper is the introduction of a measure of reciprocity in the empirical training literature. With this specific aim in mind, the questionnaire included a question that reads: "If someone does something that is beneficial to you, would you be prepared to return a favor, even when this was not agreed upon in advance?" Respondents had to choose one answer out of five categories:

- Not at all (1.0 percent)

- Not (3.3 percent)

- Maybe (9.1 percent)

- Yes (60.8 percent)

- Certainly yes (25.8 percent)

In parentheses are the percentages of the observations in our sample that choose the respective categories. A vast majority of $86 \%$ indicates that they are prepared to return a favor, but even in this group some seem to be more inclined to do so (certainly yes) than others (yes). Because the frequencies (and numbers of observations) in the categories "not at all", "not" and "maybe" are rather low, we merge these three categories. This results in a three-point scale of workers' sensitivity to reciprocity. In the sequel, we will refer to these categories as Low (= not at all, not and maybe), Intermediate (= yes) and High (= certainly yes).

The analyses in the next subsection include a set of covariates. Table A1 in the appendix presents descriptive statistics of these covariates. 
Table 1. Ordered probit estimates for level of reciprocity

\begin{tabular}{lrl}
\hline \hline Regressor & coef & s.e. \\
\hline Age & -0.006 & $(0.002)^{* *}$ \\
Female & -0.011 & $(0.041)$ \\
Migrant & 0.081 & $(0.091)$ \\
Single & -0.091 & $(0.064)$ \\
\# Children & 0.005 & $(0.017)$ \\
Primary education & -0.028 & $(0.106)$ \\
Lower Vocational & -0.139 & $(0.069)^{*}$ \\
Lower General & -0.034 & $(0.066)$ \\
Intermediate Vocational & \multicolumn{2}{c}{ reference } \\
Intermediate General & -0.040 & $(0.078)$ \\
Higher Vocational & 0.068 & $(0.057)$ \\
University & 0.170 & $(0.083)^{*}$ \\
\multicolumn{3}{l}{} \\
Observations & 3127 \\
\hline Notes: Standard errors in parentheses $*$ signifi- \\
cant at 5 percent level; ** significant at 1 percent \\
level
\end{tabular}

\subsection{Results}

Before we turn to the training equations, we first present results from an ordered probit equation in which the ordered variable sensitivity to reciprocity has been regressed on a set of commonly used background characteristics: age, gender, migration status, being single, number of children, and education. The results in Table 1 show that respondents' sensitivity to reciprocity varies systematically with respondents' age and with their level of education. Older respondents are less inclined to return a favor if someone does something that is beneficial to them. Respondents with lower vocational education are less reciprocal than respondents with intermediate vocational education while respondents with university education are more reciprocal than respondents with intermediate vocational education. There is no systematic relation between respondents' reciprocal attitudes and whether they are female, migrant, single or whether they have children.

We next turn to the relation between respondents' sensitivity to reciprocity and training participation. Table 2 gives training participation rates for workers in each of the three categories of reciprocity. The first column refers to all training participation 
Table 2. Training participation rates by sensitivity to reciprocity

\begin{tabular}{lcc}
\hline \hline & All training & $\begin{array}{c}\text { Firm-sponsored } \\
\text { training }\end{array}$ \\
\hline Low & 0.356 & 0.325 \\
Intermediate & 0.441 & 0.404 \\
High & 0.502 & 0.475 \\
\hline
\end{tabular}

while the second column is restricted to participation in firm-sponsored training. In both columns the participation rate increases with the sensitivity to reciprocity. The difference between the Low and Intermediate reciprocity groups is about .08, and between the Intermediate and High reciprocity groups is around .06. These differences are highly significant. The null-hypothesis of equal training rates between the different reciprocity groups is always rejected at the 1 percent-level or better. ${ }^{2}$ This provides $^{2}$ strong support for the relevance of the proposed reciprocity mechanism.

We next test whether this result survives when we control for differences in characteristics between workers in the three reciprocity groups. Otherwise, we cannot preclude that the result just follows from the fact that more highly educated and younger workers are more reciprocal and participate more in training. Table 3 reports estimates of three different specifications of probit equations in which training participation is the dependent variable. The top panel relates to all training participation and the bottom panel to firm-sponsored training participation. The first specification includes only dummies for reciprocity groups Low and High and has no control variables. Reciprocity group Intermediate is the omitted category. The estimates in the first column reflect the results from Tables 2 .

The second specification includes controls for respondents' gender, age, migration status, number of children, being single, and level of formal education. The coefficients for these control variables are not reported in the table. They indicate that women are less likely to participate in training than men, and that training participation decreases with age and increases with the level of formal education. Migration status, number of children, and being single have no effect on training participation. These results are consistent with other studies. The important finding of the second

\footnotetext{
${ }^{2}$ This was tested using ranksum tests, the highest $p$-value equals 0.0035 and pertains to the difference in participation in firm-sponsored training between the Low and Intermediate reciprocity groups.
} 
Table 3. Effect of reciprocity on training participation

\begin{tabular}{|c|c|c|c|}
\hline & \multicolumn{3}{|c|}{ All training participation } \\
\hline & (1) & $(2)$ & (3) \\
\hline Low & -0.086 & -0.078 & -0.074 \\
\hline & $(0.026) * *$ & $(0.027) * *$ & $(0.027) * *$ \\
\hline Intermediate & reference & reference & reference \\
\hline \multirow[t]{3}{*}{ High } & 0.061 & 0.052 & 0.051 \\
\hline & $(0.021) * *$ & $(0.021) *$ & $(0.021) *$ \\
\hline & \multicolumn{3}{|c|}{ Firm sponsored training participation } \\
\hline Low & -0.080 & -0.071 & -0.068 \\
\hline & $(0.027) * *$ & $(0.027) * *$ & $(0.028) *$ \\
\hline Intermediate & reference & reference & reference \\
\hline High & $\begin{array}{c}0.071 \\
(0.021) * *\end{array}$ & $\begin{array}{l}0.064 \\
(0.022) * *\end{array}$ & $\begin{array}{l}0.064 \\
(0.022) * *\end{array}$ \\
\hline Controls & No & Personal & Personal, Firm \\
\hline
\end{tabular}

Notes: Change in probability based on probit estimates evaluated at the sample means of the explanatory variables. Standard errors in parentheses. * significant at 5 percent level; ** significant at 1 percent level. Personal control variables: Gender, Age, Migrant, \# Children, 7 Education dummies, Single. Firm controls: 5 Firm size dummies, Firm has training center. 
specification in Table 3 is that the effects of the reciprocity variables stay almost the same and remain significant.

The third specification augments the second specification with controls for characteristics of the firm for which the respondents work. Included is one dummy variable indicating whether the respondent's employer has an own training center, and five dummy variables for categories of firm size. The coefficients for these additional controls (also not reported in the table) indicate that a worker is more likely to participate in training when the employer possesses an own training center and when the firm size is larger. This latter finding is consistent with other studies. (The finding with respect to the employer owning a training center is new, as this variable has not been included in earlier analyses.) Including these additional regressors does not change the findings of the second specification. Most important, the effects of the reciprocity variables have almost the same size and remain significant.

The results from the second and third specifications in Table 3 show that the result from Table 2 (and from the first specification) cannot be attributed to the exclusion of some relevant characteristics of the worker or the firm. The dataset does not contain information about the industries in which respondents are employed and about their occupations. Our results are biased when the reciprocity variables are picking up the effects of these omitted variables. While we have no proof to exclude this, we think it very unlikely that inclusion of industry and occupation dummies would render the reciprocity effects insignificant. This is based on the fact that inclusion of the firm characteristics "training center" and "firm size" didn't affect the results. Another possible concern is that the findings in this paper are driven by reversed causality. This would be the case if participation in (firm-sponsored) training affects workers' sensitivity to reciprocity. Given that the reciprocity question is phrased in general terms and that reciprocity is measured in only three broad categories, we judge it unlikely that a (typically short) training event shifts workers' general reciprocity attitude from low to intermediate or from intermediate to high.

\section{Conclusion}

Standard economic models predict that firms will not invest in general training and will underinvest in specific training. This result is driven by the assumption that workers behave opportunistically. In this paper we test a model in which workers may be motivated by reciprocity. We first formally show that when this reciprocal motivation 
is sufficiently strong, the firm is prepared to invest the socially optimal amounts in general and specific training. In the main part of the paper we present empirical results on the relation between workers' participation in (firm-sponsored) training and their sensitivity to reciprocity. This latter variable is measured as the response to the question whether respondents would be prepared to return a favor to someone who did something that was beneficial to the respondent. Respondents with a high score on this reciprocity question are 15 percent more likely to receive training in a 12 months period than respondents with a low reciprocity score. This is also true when a large number of control variables are included. We consider this as strong evidence in favor of the proposed reciprocity mechanism.

The second contribution of this paper is that it confronts insights from experimental economics with field data. Experimental economists are all convinced of the relevance of alternative motivations besides pure selfishness. They have shown that reciprocity can serve as a commitment device that can be efficiency enhancing. Yet, their evidence is solely based on laboratory experiments. Economists outside the circle of experimental economists are often skeptical about the external validity of results obtained in the laboratory. The results of this paper should reduce this skepticism somewhat.

\section{References}

Acemoglu, D. and J.-S. Pischke (1998). Why do firms train? Theory and evidence. Quarterly Journal of Economics 113(1), 79-119.

Acemoglu, D. and J.-S. Pischke (1999). The structure of wages and investment in general training. Journal of Political Economy 107(3), 539-572.

Aghion, P., M. Dewatripont, and P. Rey (1994). Renegotiation design with unverifiable information. Econometrica 62, 257-282.

Becker, G. S. (1962). Investment in human capital: A theoretical analysis. Journal of Political Economy 70, 9-49.

Booth, A. and M. L. Bryan (2002). Who pays for general training? new evidence for British men and women. Discussion Paper 485, IZA, Bonn.

Booth, A. and G. Zoega (1998). Do quits cause under-training. Discussion Paper Series 98/17, University of Essex, Institute for Labour Research. 
Chung, T.-Y. (1992). On the social optimality of liquidated damage clauses: An economic analysis. Journal of Law, Economics \& Organization 8, 280-305.

Fehr, E. and S. Gächter (2000). Fairness and retaliation: The economics of reciprocity. Journal of Economic Perspectives 12, 159-181.

Frazis, H. and M. Loewenstein (1999). Reexamining the returns to training: Functional form, magnitude, and interpretation. Working Paper 325, Bureau of Labor Statistics.

Kahn, C. and G. Huberman (1988). Two-sided uncertainty and Up-or-Out contracts. Journal of Labor Economics 6(4), 423-444.

Katz, E. and A. Ziderman (1990). Investment in general training: The role of information and labour mobility. Economic Journal 100, 1147-1158.

Leuven, E. and H. Oosterbeek (1999). Demand and supply of work-related training; evidence from four countries. Research in Labor Economics 18, 303-330.

Leuven, E. and H. Oosterbeek (2002a). Evaluating the effects of a tax deducation on training. Journal of Labor Economics. Forthcoming.

Leuven, E. and H. Oosterbeek (2002b). A new method to estimate the returns to workrelated training. Unpublished working paper, Department of Economics, University of Amsterdam.

Oosterbeek, H., R. Sloof, and J. Sonnemans (2001). Promotion rules and skill acquisition: An experimental study. Unpublished working paper, Department of Economics, University of Amsterdam.

Pischke, J.-S. (2001). Continuous training in Germany. Journal of Population Economics 14, 523-548.

Shavell, S. (1980). Damage measures for breach of contract. Bell Journal of Economics 11, 466-490.

Sloof, R., E. Leuven, H. Oosterbeek, and J. Sonnemans (2002). An experimental comparison of investment behavior under alternative breach remedies: The case of no-renegotiation. RAND Journal of Economics. Forthcoming. 
Stevens, M. (1994). A theoretical model of on-the-job training with imperfect competition. Oxford Economic Papers 46, 537-562.

Stevens, M. (1996). Transferable training and poaching externalities. In A. Booth and D. Snower (Eds.), Acquiring skills: market failures, their symptoms and policy responses. Cambridge University Press.

Williamson, O. (1985). The Economic Institutions of Capitalism: Firms, Markets, Relational Contracting. New York: Free Press. 
Table A1. Descriptive statistics

\begin{tabular}{lcc}
\hline \hline & Mean value & Standard deviation \\
\hline Female=1 & 0.520 & 0.500 \\
Age & 39.47 & 10.25 \\
Migrant=1 & 0.054 & 0.227 \\
\# Children & 1.04 & 1.28 \\
Primary education & 0.043 & 0.202 \\
Lower Vocational & 0.123 & 0.328 \\
Lower General & 0.142 & 0.349 \\
Intermediate Vocational & 0.292 & 0.455 \\
Intermediate General & 0.090 & 0.286 \\
Higher Vocational & 0.232 & 0.422 \\
University & 0.078 & 0.269 \\
Single=1 & 0.129 & 0.335 \\
Training center=1 & 0.383 & 0.486 \\
Fsize [1, 10) & 0.207 & 0.405 \\
Fsize [10, 50) & 0.230 & 0.421 \\
Fsize [50, 100) & 0.102 & 0.302 \\
Fsize [100, 200) & 0.106 & 0.309 \\
Fsize [200,++) & 0.311 & 0.463 \\
Fsize unknown & 0.044 & 0.205 \\
Observations & & \\
\hline
\end{tabular}

